\title{
Trauma, Development, Dispossession: “Telling the Story" of Refugees and Suffering in Somali Ethiopia
}

\author{
Christina Zarowsky
}

\begin{abstract}
Ethnographic research about "the refugee experience" of Somalis in eastern Ethiopia is discussed, focusing on interactions of returnees with relief and development agencies, the story of one community, and a discussion of some Somali emotion words. Exclusively psychological or psychiatric approaches to working with refugees may not provide a satisfactory point of access to displacement-related distress among Somali refugees. Highly individualizing models of suffering, focusing on psychological distress, are of only limited salience to populations of Somali refugees and returnees in the Horn of Africa-politics, poverty, and perceived collective injustice must be addressed in conjunction with any exploration of emotional distress and personal suffering.
\end{abstract}

\section{Précis}

La recherche ethnographique à propos del' "expérience de réfugiés" des Somalis en Ethiopie Orientale est présentée et discutée, avec uneattention particulière portée sur les interactions des gens qui retournent au pays avec les agences ayant pour rôle de soulager leur traumatisme et de fortifier leur développement. Une approche exclusivement psychologique ou psychiatrique du travail avec les réfugiés risque de ne pas fournir une prise satisfaisante sur la détresse associée au déplacement chez

Christina Zarowsky, M.D., is a Ph.D. candidate in the Department of Anthropology, McGill University, Montréal, and a researcher at the Douglas Hospital Research Centre, Psychosocial Research Division, Montréal.

This research was made possible by a doctoral fellowship from the Social Sciences and Humanities Research Council of Canada, and a research grant from the Faculty of Graduate Studies, McGill University, Montréal. les réfugiés Somalis. Les modèles hyperindividualisants en matière de détresse morale, concentrant leur attention sur la souffrance psychologique, ont une pertinence limitée en ce qui concerne les populations en situation de refuge et en situation de retour dans la Corne de l'Afrique. La politique, la pauvreté, l'évidente injustice collective doivent être prises en considération en conjonction avec toute exploration dela détresse émotionnelle et des souffrances personnelles.

\section{Introduction}

A physician friend was recently asked by an immigration lawyer to do a medical exam on a client who had been refused refugee status in Canada. The key question was whether this claimant could be diagnosed as suffering from Post-Traumatic Stress Disorder (PTSD). The client's story and claims of persecution were irrelevant. The physician was relieved to find physical signs consistent with torture, but the most salient issue was psychic-not physical-trauma.

This vignette seems to suggest a limited shift in one practical definition of "refugee" in Canada, from having a reasonable fear of persecution from which the country of origin is unlikely to defend the claimant, to having a diagnosable mental illness. In this instance, available to support a diagnosis of PTSD appears to be considered more reliable than that supporting alleged political or other persecution. The story recounted by the physician is consistent with a prevalent academic and popular view of refugee suffering as trauma, specifically as psychological trauma. It also demonstrates one possible endpoint for a trauma model of the refugee experience. Despite insistence from proponents of the PTSD model that they do not suggest that PTSD and its therapy encompass the whole of the refugee experience (Friedman and Jaranson 1994), and some psychiatrists' qualification that "trauma" must involve the individual's feeling both terrified and trapped according to their own framework (Dr. Clare Pain, personal communication), "trauma" and PTSD have come to be seen as a general model of "the" refugee experience. In the trauma model, the core of the distress experienced by refugees is the psychophysiological constellation of symptoms associated with the memory of highly disturbing events. Appropriate responses include limited pharmacotherapy and more or less intensive psychotherapy directed at encouraging the individual to "tell the story" of their trauma so that distressing memories and emotions can be healed.

The current emphasis on psychosocial effects of trauma and displacement reflects, in part, an uneasiness with a depersonalizing view of refugees as, in a sense, political and bureaucratic inventions, subject to the whims of governments and other organizations and devoid of personal histories and emotional lives. However, the endpoint of a diagnosis of disease, mental or otherwise, is perhaps even more destructive of the agency of people identified as refugees. A strength as well as limitation of the medical model is its depoliticization and desocialization of many forms of distress. This allows illness to be approached from other than a moral dimension of, for example, punishment for transgression. This process often allows taboo issues to be addressed, but it also imposes an obligation of dependency ("compliance") on patients, and it systematically blocks exploration of links to other domains of experience, especially political and economic contexts, which may in fact be critical both to under-

Refuge, Vol. 16, No. 5 (November 1997) 
standing and resolving given problems.

In this paper I wish to suggest that for some Somali refugees in the Horn of Africa, as well as for the agencies with which refugees and returnees interact, the framework for giving structure, meaning, and ultimately closure to "the refugee experience" is not that of individual psychological trauma. This paper is based on 14 months of anthropological fieldwork with Somali refugees, returnees, and agencies involved in relief and development, in eastern Ethiopia.I present an overview of some of my ethnographic findings about "the refugee experience" of the Somali populations, focusing on interactions with relief and development agencies, the story of one community, and a discussion of some Somali emotion words. My findings suggest that in Ethiopia, the more salient frameworks are "development" on the one hand (in contexts where relief and development agencies are the dominant institution), and, for the communities I focused on, a story of collective suffering framed in terms of history, justice, and dispossession, rather than in terms of individual loss or distress. Private suffering and personal memories certainly exist and can be spoken about, but these stories were almost never mentioned, let alone told, in the public discussions or private interviews about "the refugee experience."

An implication is that exclusively psychological or psychiatric approaches to working with refugees may not provide a satisfactory point of access to displacement-related distress among Somali refugees, even if in some cases a trauma or PTSD model and approach may ultimately prove helpful. Highly individualizing models of suffering, focusing on psychological distress, are of only limited salience to populations of Somali refugees and returnees in the Horn of Africa-politics, poverty, and perceived collective injustice must be addressed in conjunction with any exploration of emotional distress and personal suffering. This was true even in the two cases locally identified as "madness" related to the history of displacement: any healing, it was emphatically insisted, would arise not from talking about memories and emotions, but from restitution. In what ways and to what extent the models of dispossession and economic development remain relevant to resettled Somali refugees is unclear. However, if the trauma model is to be usefully applied among Somali refugees, it is necessary to explore the historical, cultural, and current contexts, and then to decide in each case whether or not a trauma or PTSD model is appropriate.

\section{Development}

The issue of refugees in general and refugee suffering in particular is only a small part of the discourse of "development." However, the rules and assumptions of the broader discourse also apply to interactions involving refugees. In most of the world, this is the context within which most interactions involving refugees and their would-be helpers occur. It is also a context which shapes the experience and expectations of refugees, whether or not they eventually interact with mental health practitioners.

The meanings of "refugee" and "suffering" are constructed and contested in many settings. These meanings and their implications are then brought into other settings, but they are never fixed. These moments in the trajectories of mental health workers, researchers, relief agency personnel and so on, on the one hand, and people who had been refugees on the other, can be examined in terms of Wittgenstein's concept of a language game, in this case related to the words "refugee" and "suffering." A language game is a process of creating consensual meaning in social interactions, where participants bring in assumptions, memories, and expectations around words, ideas, and issues, and negotiate or hammer out new social realities and new networks of meaning (Ulin 1984, 26-41).

One such setting is a holding camp for returnees-returning refugees-in the city of Dire Dawa in eastern Ethio- pia. In this setting, psychological trauma is not salient, neither for the agency personnel distributing "repatriation packages," nor for the predominantly Somali returnees receiving the packages. Nor, however, is politics drawn on in this context, even though the reasons for flight and for return were both political and economic-the war between Ethiopia and Somalia in 1977-78, the political chaos and violence plus localized droughts at the downfall of the Mengistu regime in 1991, and relative stability in Ethiopia plus diminishing economic opportunities and increasing political intolerance of refugees in the neighbouring country of Djibouti in 1995. In camps of refugees from Somaliland in the far east of Ethiopia, almost every refugee with whom I spoke referred to the political situation in the capital city of Hargeisa as the determining factor for flight and future return. In contrast, returnees in Dire Dawa drew almost exclusively on bureaucratic definitions and on the suffering caused by poverty to pursue their demands for assistance. The language game is in part about legitimacy or "genuineness" - both to recognize and validate experience, and to obtain or deliver resources. Not all dimensions of "refugee" or "suffering" are in evidence here, but the language game and its context are very different from those in Canada, of which the opening vignette in this paper is one example. Neither "capital P" politics nor psychology and trauma are particularly relevant in the returnee camp. The larger language game, of which "refugees" and "suffering" are a part, is emphatically that of "Development."

\section{Returnee Accounts}

How did returnees participate in this language game where their needs were allegedly primary but the rules were set almost entirely by others? Here is an excerpt from one interview, whose tone and content are illustrative of the dozens of group discussions and individual interviews held with different train loads of returnees over the summer of 1995. The discussion is quite 
blunt on one level, but the men do not allow it to stray beyond a few key points which they wish to emphasize-and neither does my Somali interpreter and friend, Rosa, who refused to engage the men in a discussion of politics once they had evaded a tentative attempt to do so. The dominant themes are poverty and the obligation-imposed by humanitarianism-to assist. These themes reflect the discourse of the agencies themselves, including agency concerns about "dependency." Governments are only peripherally involved-the relief agencies are considered the relevant sources of assistance. Agencies are the de facto state in refugee situations; and appear to remain so in the eyes of returnees.

Where "the men" are speakers, one or more individuals were speaking on behalf of the group as opposed to clearly on their own behalf.

\footnotetext{
Ahmed: They are giving me only 30 birr ${ }^{1}$ and a bag of wheat.

Rosa: That's enough.

Ahmed: I want more. Can she help me? (gesturing at me)

Rosa: I don't think so.

Men: We're telling UNHCR to give us instruments to start farming, but while the crop is growing we need to eat.
}

At this point I enter the discussion more directly, and decide to confront the men in order to try to "get past" the repeated requests for assistance. I wondered, what is the underlying reasoning?

\begin{abstract}
Christina: Why should UNHCR and the government give you anything? Men: It's not the government, but the NGO's stand for human rights. It's very human. When we face a drought or problems, they can help us.
\end{abstract}

Ahmed: I had a shop. It was destroyed, now I need help from UNHCR.

Mukhtar: Don't speak only for yourself, speak for others in your situation as well.

Men: No one wants to be a refugee. Everyone wants to work, but there was drought and war so we had to leave. Now we are back in our country, the soil is good, there is no war... now if NGO's and UNHCR can give us a hand-seeds, instruments, oxen, water; and if they give us a ration to wait while the crop is growing.

Christina: Who should be responsible for helping? Themselves, family, government, NGO's, the UN?

Men: What we think, is UNHCR, because they're standing for human [rights]. They're working with the government, but its UNHCR and NGO's.

Christina: Where do [you] think UNHCR gets money?

Men: They [UNHCR] have a lot of things, machines; even if there's a drought they don't suffer and can get something from the earth ... Because, when a person can help himself, then he can help others. So UNHCR has helped themselves, and now they can help others.

Jama: We need your help. We are talking a lot, but we need your help.

\section{The Refugee Experience as "Development"}

The Somali word for refugee-qoxotiis relatively new. Its meanings are shaped both by Somali notions and experiences of flight, war, justice, and need, and by outside notions and social organization; specifically, by the UN Convention definition of refugee, and by the experience of refugee camps and refugee relief agencies. The word qoxoti literally means "people who flee before the mouth of a gun" (Sidney Waldron, personal communication). It implies dislocation, forced migration, and fear, but also dispossession and poverty that is outside the normal framework of mutual assistance, or the possibility of recovery through mechanisms such as livestock raiding. Central images are of destitution on the one hand, and on the other hand of the appropriateness of looking to outsiders for assistance. The latter aspect reflects the fact that the civil and other wars which led to the creation of the category goxoti also featured highly visible involvement by international relief agencies.
The semantic network around the word "refugee" has two dimensions or axes:

1) geopolitical, evoking words such as nation, borders, migration, sovereignty, denationalization; and

2) moral-experiential, having to do with rights and obligations, notions of the self, experience, and evoking words such as persecution, suffering, duty, charity, humanitarianism.

In actual relief distribution settings in Ethiopia, most agency personnelboth Ethiopian and international-are not interested in geopolitics. Rather, they are motivated by pity and the desire to help the unfortunate on the one hand, and by personal livelihood concerns and the culture of relief work on the other. This relief work culture currently includes an official concern to avoid "creating dependency" among refugees, returnees, and other groups receiving aid, and the view that a defensive and suspicious stance is necessary to minimize the amount of cheating by people pretending to be refugees. Finally, the concrete context of this interaction-the distribution of food and money to thousands of individuals-brings in a bureaucratic and logistic dimension which is officially dismissed as irrelevant to the real business of helping people. In fact, these logistic issues place fairly rigid constraints on the kinds of interactions possible, limiting the opportunity for creating individual empathic connections which impose perceived obligations of assistance.

Observation and interviews at the holding camp revealed the absolute centrality of the identities "refugee" and "returnee" and of the attendant benefactor/dependent hierarchy in this setting. Almost all the individuals who approached me or whom I approached asked for help, citing their need and agencies' "humanitarianism" as reasons. In contrast, although virtually all of my friends and contacts in Dire Dawa had been refugees themselves or had immediate family members who were or had been refugees, 
the discourse of need, humanitarianism, and suffering was conspicuously limited in these situations where other institutions-family, friendship, occupation-provided structure and meaning. This is not to say that when the "refugee relief system" was the central institution individuals lie or exaggerate-nor that their "real" feelings are apparent only in one or another setting - but that context is critical to an understanding of the larger significance of particular findings.

The language game of development provides one framework within which the experience of Somali refugees, including suffering, can be both meaningfully discussed and, perhaps more importantly, acted upon. This framework is far from ideal, but it at least acknowledges the grinding poverty which is central to the experience of most African refugees.

\section{Dispossession}

In the transient world of the returnee holding camp, life histories of individuals, families, and communities are glimpsed through the counterpoint of a language game around need, obligation, humanitarianism, and legitimacy. Despite having very little control over the material or rhetorical structure of this world, returnees shape its particular manifestations through their own accounts, claims, and actions, drawing on their individual and collective experiences as well as on more persistent themes and strategies arising from Somali, Ethiopian, and agency cultures. Hints of alternative systems of meaning emerge from these interactions, but such alternative systems can be more clearly seen in contexts where the dominant institution is not the "refugee relief system."

In this section I wish to present some aspects of one community's story. It is a story of dispossession, demoralization, and struggle. History is central to this story. Here, "history" is chronology of events, memory, ideology, a way of codifying and presenting systems of value, a way of creating society and community, and a program of action. It is, in part, a "mythico-history" (Malkki 1995, 52-54). The "refugee relief system" is an integral part of this world, butneither the optimistic rhetoric of "repatriation" and "development," nor the concerned rhetoric of "trauma," begin to capture its range. While it appears on the surface to be much more traditional and timeless than the ad hoc communities of refugee camps or resettled populations, this community is also an "imagined community" (Andersen 1991), where fourteen years in refugee camps are of very minor importance in accounts seeking to convey history, create meaning, and build lives.

\section{Migration and Return}

The village of Beer Weyn (a pseudonym) is about $25 \mathrm{~km}$ or 2 to 4 hours by bus and pickup truck from the city of Dire Dawa. The current population of the village is approximately 3,000, with at least another 1,000 former residents settled in the nearby town of Magaala, primarily in the neighbourhood known as Ganda Beer Weyn. The entire population of Beer Weyn left the village after the 1977-78 Ogaden War in which Somalia tried to annex the primarily Somali areas of eastern Ethiopia. During the war itself this village was a centre of Somali resistance, although many villagers claim that they just wanted to be left in peace to work their lands. Many villagers fled to the surrounding countryside to join their pastoralist kin, but returned to the village and their farms after several months to a year. In 1979, the entire community left again. Many of the returnees I spoken to in the Dire Dawa returnee camp were returning to Beer Weyn, Magaala, and neighbouring villages.

The story of the flight and return was told by men and women, elders as well as youth who had been infants at the time. It goes as follows. In the aftermath of the war, the Ethiopian government decided to expand the military base adjacent to the village, and began to expropriate the orchards and farmlands of this agropastoralist commu- nity. Initially, farmers were offered compensatory lands south of the capital city of Addis Ababa, several hundred $\mathrm{km}$ to the south west. These lands in turn had been expropriated from other communities. A few families accepted this offer and relocated, only to be evicted by the original owners after the fall of the Derg in 1991. The majority refused to leave their highly productive lands, although they say they cooperated with the requests of the government to provide evidence of the size and quality of their holdings in order that compensation could be calculated. The villagers say that one day during this negotiation process the military arrived in Beer Weyn. The community was told to gather together. They were surrounded by soldiers who pointed their guns at the villagers, who were then asked if anyone objected to leaving. They were told to evacuate within 12 hours. Bulldozers arrived and destroyed the homes and shops, and people fled, some to Djibouti, others to Somalia, depending on contacts and the availability of transport at crossroads towns. Many people were killed or died during the flight. A few stayed in the area, living in the forest or staying with pastoralists, returning to their lands and facing repeated beatings until, according to the villagers, the army realized these individuals were mad and harmless. A tiny minority of shopkeepers were allowed to stay, to service the military base and the train that stops in the village on the way to Addis; these faced very strict controls on travel, visiting, and other activity during the period 1979-91. The majority fled to Djibouti, where they stayed in UNHCR camps until 1988 or 199195. By 1988, the welcome in Djibouti had worn thin and a first round of repatriation occurred. Most Beer Weyn residents, however, refused to leave the camps until they were assured that their farmlands would be returned. With the fall of the Derg and the installation of the new EPRDF (Ethiopian People's Revolutionary Democratic Front) government came promises of return of expropriated lands, and the 
majority of Beer Weyn villagers began to return, with or without UNHCR assistance.

In 1997, the community is still in limbo. The government has not returned the farmlands, though negotiations continue. Villagers identify the land as "Ahmed's garden," "Amina's garden," and so on, and express their impotent anger at watching the military "eat their lands," selling crops from expropriated lands while allowing other orchards to become unproductive through neglect. They do not quite believe that they will ever get their lands back, but when asked what they would do if the government clearly said the lands would not be returned, villagers reply that the government will never say this outright because then they would face an armed uprising. The military base itself is critical to the survival of the village, as it is the main market for the shops, and the brothels serving the base are an important market for the firewood gathered by many villagers as their main source of livelihood. Some villagers are soldiers at the base, as the local clan militia was in large part incorporated into the EPRDF forces. Resentment against both the base and the men and women working and guarding the lands is surprisingly low; anger is quite clearly focused on the government and specifically the military leadership, who are felt to be holding on to the lands out of greedboth for the profits obtainable from the land, and merely for the possession itself.

People survive on the edge of destitution, making a living by gathering firewood-seen as one step above begging, and a constant reminder that this is not "a human life"-or portering bundles of contraband for smugglers in the area. When I asked why they don't leave, I was in turn asked where they should go. The surrounding land looks empty but is in fact used to its carrying capacity by pastoralists, and in any case villagers say they have both lost the skills for living off the land, and have come to expect health care, water, and education as integral to "a human life." The rhetoric of development has convinced them, leaving them, as they themselves note, worse off than their pastoralist kinsmen who also do not have these services but who do not want them, either. Agricultural land nearby is full as well. In a country refederated on ethnic lines, moving elsewhere altogether is problematic. Finally, and as important as the practicalities of survival, is pride and anger-these are their lands, from which they have been unjustly dispossessed.

This, then, is a community which has been "repatriated" and "reintegrated," for whom, in the eyes of the refugee relief system, the identity of "refugee" has been extinguished. In the eyes of the community itself, the war is not yet over. The core of the refugee experience for this community, however, is not the horror of flight, nor the long years in camps, which in fact are seen as a kind of golden time when children could go to school and there was enough to eat. The centre of this community's story now and since 1979 is dispossession, injustice, poverty, and living an inhuman life.

\section{Where is a Poor Man to Get Happiness?}

This rhetorical question was the answer I received when I asked one old man if he was niyed jabay-demoralized/hopeless/dejected; literally, "will broken." I begin a discussion of some Somali emotion words only at this point in the paper because emotional states, identified as such, are not the central concern of this population. Emotion is important and rich in Somali life, although this is only hinted at in much of the existing literature, which focuses on politics and economics. The ubiquitous references to the importance of poetry in Somali life and politics indicate that aesthetics and emotion are not peripheral interests of elite groups (Andrzejewski and Lewis 1964; Cassanelli 1982; Lewis 1961; Samatar 1982). These very references, however, linking poetry with politics, warfare, peacemaking, and religion, as well as love, also make the point that I wish to stress: "emotion" is always embedded in life. There are abstract terms for what are considered emotional states, and I will list and briefly describe some of these states, but these words are always linked to concrete experience. Many of the words whose semantic networks I explored were linked to loss - of land, of love, of family, of livelihood. However, in interviews and life histories, the definitions of these concepts always included reference to specific examples, which vary with gender, social class, and life experience; lists of synonyms and nuances of the emotional state per se were not offered.

For Beer Weyn residents, the loss of the farmlands was the central motifthis is inseparable from any discussion of niyed jab; this is what murugo means (thinking or rumination about an insoluble problem or loss; sadness or depression), or marrora dilla' (anguish caused by sudden overwhelming loss of something precious, and characterized by rage, perceived powerlessness, and uncontrolled behaviour ranging from weeping to violence to madness). Murugo and marrora dilla' in the abstract, divorced from content and context, are meaningless words. For middle class women, niyed jab is linked to a husband marrying a second wife. For mothers, niyed jab is linked to the repeated deaths of infants, and for both mothers and fathers, to being unable to provide a decent life for one's children. Other related words arose in other conversations: argegah (sudden shock and the subsequent physical and behavioural reactions; argegah ranges from waking from a nightmare, to the horror experienced at seeing the murder of one's relatives); wareer (thinking/ anxiety/dizziness/confusion, caused either by a febrile illness or by life problems); waaliy (madness, which can occur subsequent to a physical illness, or for no known reason-"sent by God," or as one of three possible sequelaerecovery, niyed jab, or madness-of argegah or marrora dilla').

A second set of words is on the positive end of the emotional spectrum, including niyed fii'an (good morale; a sense of being able to provide for one- 
self and one's family without being dependent of frequent or constant help; a general sense of well-being); farxad (joy, usually finite and attributable to a particular cause); fi'il (a spirit of action that enthuses or activates warriors, as well as, for example, athletes); hammid (passion/desire/love/ longing/yearning, expressed in poems about the beauty and fertility of Beer Weyn and characterizing men's reactions to hearing these poemslove of home; also sexual desire and passion, and passion for activities, including contraband). The root word of both hopelessness/demoralization and well-being, niyed, can be glossed as mind or attention, the ability to focus, will; it was often said to be more or less synonymous with qalbi, or "heart" in the sense of focus of desire and love.

Spirit possessions (zar or wadaado) were not identified as being linked to, much less caused by, dislocation or loss or frustration, although they were said to be more common in the refugee camps than now. Conversely, although madness can happen for no apparent cause, and although individuals can be more or less prone to niyed jab or murugo, I did not hear of the existence of anything approaching the psychiatric notions of "endogenous" or purely biochemical depression. People manifesting such symptoms seem to be more likely to be thought to suffer from zar or wadaado, although the latter form of possession tends to present with somatic rather than emotional or behavioural symptoms. A reason offered for the apparent decline in possession states is that "the new generation doesn't believe in it, so it can't catch you; when people get sick now they go to doctors".

It is clear even from this brief catalogue that there is a rich vocabulary of emotion, and that people learn this vocabulary. It is learned through hearing and discussing life problems and issues. You don't talk about feelings, I was told; you talk about how to solve the problems, or how to live with them. Another way of coping with problems and suffering is to distract the mind, whether through laughter, or singing, or chewing qat, or by deliberate "forgetting" or not thinking about problems. One discussion with a women's group put it like this:

Too many problems and too much thinking makes you wareer (thinking/anxiety/dizziness/confusion), but it doesn't happen all at once, it happens bit by bit. So we try to forget about the past problems.

However, they do not forget about past problems. Young men who were infants at the time of flight can recount the story in minute detail. What is done, is to frame the "past problems" - and the present ones, for that matter-in terms that provide a meaningful story and framework for action, whether of history and (in)justice, or in reference to stories about Muslim heroes, saints, and martyrs, or in other terms that reinforce the sense of community and the meaningful place of an individual in this community and its trajectory. Religion is an important source of consolation, and also of the norm of samir iyo iman, acceptance in faith and serenity. This simultaneous consolation and instruction is not always conflict-free, as another discussion with women revealed. Women are considered less likely to suffer from niyed jab or murugo in the case of death of a loved one because they can cry and verbalize their unhappiness, but when pressed to say whether it is better to cry or to accept the will of God, the women said it is better to accept the will of God.

\section{Psychosocial Effects of Trauma and Dislocation}

It is now possible to begin to see where notions of "trauma" may enter into the experience of this community, and, I suggest, others like it. To begin with, the story of Beer Weyn suggests, once again, that we should stop ignoring the "social" in "psychosocial" (see e.g., Boothby 1994; Eisenbruch 1991; Jenkins 1991).

Second, the ways in which madness and spirit possession were presented suggest that, in this community, an inability to link emotion and behaviour with specific events on the one hand, or an inability to "metabolize" an initial overwhelming shock into a coherent place within a collective story on the other, are, first, the exception, and second, truly outside of authentically human experience, in the realms of spirits and insanity rather than constituting the "real" core of "the" refugee experience. With respect to individuals thought to be possessed or mad, the preeminent concerns of other members of the community were to bring them back into the human community, whether through culturally sanctioned rituals of spirit appeasement, or through repair of or compensation for the initial injury, in this case, the loss of farmlands.

This suggests, in turn, that therapeutic interactions with distressed Somali refugees in Canada might take a number of directions. One might be to find ways of situating an individual's experience, distress, and current situation in a collective (family? clan? occupation? gender?) story which is both culturally and emotionally meaningful and, of critical importance, able to inform action. Individuals whose experiences or "trauma" prove to be outside the realm of such a collective story and program of action may indeed be well served by a variation of a "trauma" model, precisely because it is foreign, outside the rules, and, as discussed in the introduction, allows taboo issues to be addressed. Even here, however, the powerful stories told by Beer Weyn and other returnees and refugees suggest that a narrow focus on feelings divorced from concrete action will be both incomprehensible and ineffective: the cause of distress-niyed jab, murugo, and even madness-in Beer Weyn and elsewhere is not traumatic memory, but remembered, and unresolved, dispossession. If the problem in "average" cases is to live "a human life" and in extreme cases to bring the person back to the human realm, then the solution must involve the mundane particularities of human life. 
Notes

1. Approximately \$7 Canadian.

References

Andersen, Benedict. 1991. Imagined Communities: Reflections on the Origins and Spread of Nationalism. New York: Verso.

Andrzejewski, B. W., and I. M. Lewis. 1964. Somali Poetry. Oxford: Clarendon Press.

Boothby, Neil. 1994. "Trauma and Violence Among Refugee Children." In Amidst Peril and Pain: The Mental Health and Welland Pain: The Mental Health and Well-
Being of the World's Refugees, edited by Anthony J. Marsella, Thomas Bornemann, Solvig Ekblad, and John Orley, 239-59. Washington, DC: American Psychological Association.

Cassanelli, Lee. 1982. The Shaping of Somali Society: Reconstructing the History ofa Pastoral Society: Reconstructing the History ofa Pastoral
People, 1600-1900. Philadelphia: University of Pennsylvania Press.

Eisenbruch, Maurice. 1991. " From Post- Traumatic Stress Disorder to Cultural Bereavement: Diagnosis of Southeast Asian Refugees." Social Science and Medicine 33, 673-80.

Friedman, Matthew, and James Jaranson. 1994. "The Applicability of the Posttraumatic Stress Disorder Concept to Refugees." In Amidst Peril and Pain: The Mental Health and Well-Being of the World's Refugees, edited by A. J. Marsella, T. Bornemann et aI., 20727. Washington, DC: American Psychological Associa Psych
tion.

Jenkins, Janis Hunter. 1991. "The State Construction of Affect: Political Ethos and Mental Health among Salvadorean Refugees." Culture, Medicine and Psychiatry 15, no. 2, 139-65.

Lewis, loan M. 1961. A Pastoral Democracy-A Study of Pastoralism and Politics among the Northern Somali of the Horn of Africa. London: Oxford University Press.

Malkki, Liisa H. 1995. Purity and Exile: Violence, Memory, and National Cosmology Among Hutu Refugees in Tanzania. Chicago: University of Chicago Press.

Samatar, Said S. 1982. Oral Poetry and Somali Nationalism: The Case ofSayyid Mahammad Abdille Hasan. Cambridge: Cambridge University Press.

VIin, Robert C. 1984. Understanding Cultures.

Austin, TX: University of Texas Press. :J

\section{CRSIYLP PUBLICATIONS BOOKS}

From Being Uprooted to Surviving: Resettlement of the VietnameseChinese "Boat People" in Montreal,1980-1990 Lawrence Lam (1996) $\$ 18.95$

Asylum-A Moral Dilemma w: Gunther Plaut (co-published with Praeger Publishers) (1995) \$19.90

Refugee Rights; Report of a Comparative Survey James C. Hathaway and John A. Dent (1995)

Legitimate and Dlegitimate

Discrimination: New Issues in Migration Edited by Howard Adelman (1995) $\$ 22.95$

African Refugees: Development Aid and Repatriation Edited by Howard Adelman and John

Sorenson (1994)

$\$ 39.90$

Immigration and Refugee Policy: Australia and Canada Compared Edited by Howard Adelman, Lois Foster, Allan Borowski and Meyer Burstein (1994)

Volume One: Context, Policy and Implementation \$24.95 Volume Two: Settlement and Impact \$24.95

Breaking Ground: The 1956 Hungarian Immigration to Canada Edited by Robert $\mathrm{H}$. Keyserlingk (1993) \$6.99

Taking Refuge: Lao Bnddhists in North America Penny Van Esterik (1992) $\$ 12.95$

Refuge or Asylum: A Choice for Canada Edited by Howard Adelman and C. Michael Lanphier (1991) $\$ 18.95$

Refugee Polley: Canada and the United States Edited by Howard Adelman (1991) $\$ 20.95$

Soviet-Jewish Emigration and Resettlement in the 19908 Edited by Tanya Basok and Robert J. Brym (1991) \$4.99

\section{REPORTS}

Paths to Eqnity: Cultural, Linguistic, and Racial Diversity in Canadian Early Childhood Education Judith Bernhard, Marie Louise

Lefebvre etal. (1995) \$18.95

Cambodian Refngees in Ontario: An Evaluation of Resettlement and Adaptation Janet McLellan (1995) $\$ 12.95$

Somali Refugees in Toronto:

A Prorde Edward Opoku-Dapaah (1995) \$12.95

Refugee Families and Children: A Directory For Service Providers in Metro Toronto John Morris and Lydia Sawicki (1995) \$6.95

Adaptation of Ghanaian Refugees in Toronto Edward Opoku-Dapaah (1993) $\$ 12.50$

Report on the Workshop for African Commnnity Gronps in Toronto Edward Opoku-Dapaah (1992)

Directory of African Community Groups in Toronto Edward Opoku Dapaah (1992) $\$ 12.50$

\section{OCCASIONAL PAPERS}

Fading Hopes: Struggles for Survival Among Cambodians Repatriated from Thai Refugee Camps Janet McLellan (1996)

The Genesis of a Domestic Refugee Regime: The Case of Hnngary Edited by Howard Adelman. Endre Sik and Geza Tessenyi (1994)\$14.95

So That Rnssia Be "Saved": AntiJewish Violence in Russia, Its Roots and Conseqnences Tanya Basok and Alexander Benifand (1993)

The Refugee Crisis in Russia Rozalina Ryvkina, Rostislav Turovskiy and Robert Brym (1993)

Please send your orders to: Centre for Refugee Studies Yor. University Suite 333, York Lanes. 4700 Keele St. Toronto ON M3J IP3 